\title{
Optimizing a culture medium for biomass and phenolic compounds production using Ganoderma lucidum
}

\author{
Carlos Andrés Zárate-Chaves ${ }^{1}$, María Camila Romero-Rodríguez ${ }^{1}$, \\ Fabián Camilo Niño-Arias ${ }^{2}$, Jorge Robles-Camargo ${ }^{2}$, Melva Linares-Linares ${ }^{1}$, \\ María Ximena Rodríguez-Bocanegra ${ }^{1}$, Ivonne Gutiérrez-Rojas ${ }^{1}$ \\ ${ }^{1}$ Unidad de Investigaciones Agropecuarias, Departamento de Microbiología, Facultad de Ciencias, \\ Pontificia Universidad Javeriana, Bogotá, D.C., Colombia. \\ ${ }^{2}$ Grupo de Investigación Fitoquímica, Universidad Javeriana, Departamento de Química, \\ Facultad de Ciencias, Pontificia Universidad Javeriana, Bogotá, D.C., Colombia.
}

Submitted: July 11, 2011; Approved: July 2, 2012.

\begin{abstract}
The present work was aimed at optimizing a culture medium for biomass production and phenolic compounds by using Ganoderma lucidum. The culture was optimized in two stages; a PlackettBurman design was used in the first one for identifying key components in the medium and a central composite design was used in the second one for optimizing their concentration. Both responses (biomass and phenolic compounds) were simultaneously optimized by the latter methodology regarding desirability, and the optimal concentrations obtained were $50.00 \mathrm{~g} / \mathrm{L}$ sucrose, $13.29 \mathrm{~g} / \mathrm{L}$ yeast extract and $2.99 \mathrm{~g} / \mathrm{L}$ olive oil. Maximum biomass production identified in these optimal conditions was $9.5 \mathrm{~g} / \mathrm{L}$ and that for phenolic compounds was $0.0452 \mathrm{~g} / \mathrm{L}$, this being $100 \%$ better than that obtained in the media usually used in the laboratory. Similar patterns regarding chemical characterization and biological activity towards Aspergillus sp., from both fruiting body and mycelium-derived secondary metabolites and extracts obtained in the proposed medium were observed. It was shown that such statistical methodologies are useful for optimizing fermentation and, in the specific case of G. lucidum, optimizing processes for its production and its metabolites in submerged culture as an alternative to traditional culture.
\end{abstract}

Key words: Medium optimization, Ganoderma lucidum, Plackett-Burman, central composite design, phenolic compounds.

\section{Introduction}

Ganoderma lucidum is a Basidiomycetes fungus from the order Polyporales, which is widely known in traditional western medicine for its immunomodulating properties and its antitumor effects. It has been shown that this fungus is useful in treating and preventing high blood pressure, hyperglycemia, hepatitis, chronic bronchitis, asthma, heart diseases, cancer and HIV (Mei-Chun et al., 2006; Muller et al., 2006; Lai et al., 2010; Leskosek-Cukalovic et al., 2010), as well as its great effect on slowing down cell senescence and its antioxidant content (Sudheesh et al., 2010). G. lucidum's beneficial properties are related to a broad variety of bioactive compounds present in the fruiting body, mycelium and spores. Polysaccharides, triterpens, phenols, steroids, amino acids, nucleosides and nucleotides can be found amongst such compounds. The first two have been most studied, more than 100 compounds have been identified as having biological activity; $\beta-1-3$ and $\beta-1-6$ D-glucans are the polysaccharides having the greatest biological activity and $\mathrm{A}$ and $\mathrm{B}$ ganoderic acids in the triterpens (Russell and Paterson, 2006; Leskosek-Cukalovic et al., 2010).

Phenolic compounds are widely distributed amongst living organisms, particularly in plants where they play an

Send correspondence to I. Gutiérrez-Rojas. Unidad de Investigaciones Agropecuarias, Departamento de Microbiología, Facultad de Ciencias, Pontificia Universidad Javeriana, Carrera 7a 43-82, Edificio Carlos Ortiz, S.J. Oficina 608, Bogotá D.C., Colombia. E-mail: ivonne.gutierrez@javeriana.edu.co. 
important role in response to pathogenic agents, having antibacterial and antiparasitic activity, sometimes being highly specific (Del Signore et al., 1997). Such compounds have one or more aromatic rings, with one or more hydroxyl groups; they can be found as simple molecules (phenolic acids, phenylpropanoids, flavonoids) or as highly polymerized compounds (lignin, melanin, tannins) and most of their biological effects have been attributed to their antioxidant activity (Barros et al., 2009). Even though their presence has been reported in many species of edible and non-edible macromycetes, such as Amanita rubescens, Boletus edulis, Cantharellus cibarius, Fistulina hepática, Hydnum repandum, Hygrophoropsis aurantiaca, Hygrophorus agathosmus, Hygrophorus olivaceo-albus, Laccaria amethystine, Lactarius aurantiacus, Lactarius salmonicolor, Lepista inversa, Mycena haematopus, Russula caerulea, Russula cyanoxantha, Russula delica, Russula sardonia, Suillus bellini, Suillus collinitus, Suillus granulatus, Suillus luteus, Suillus mediterraneensis, Tricholoma atrosquamosum, Tricholoma equestre, Tricholoma sulphureum and Tricholomopsis rutilans (Ribeiro et al., 2008; Barros et al., 2009; Vaz et al., 2011), these compounds have been little studied in the genus Ganoderma. It has been reported that polyphenols are the principal antioxidant components in methanol extracts of G. lucidum (16.5 to $27.9 \mathrm{mg} . \mathrm{g}^{1}$ ) (Saltarelli et al., 2009) and of G. tsugae (24.0 to $35.6 \mathrm{mg} / \mathrm{g}$ ) (Mau et al., 2005), such values being similar to those reported for other macromycetes such as Antrodia camphorata $(38.0 \pm 0.7 \mathrm{mg} / \mathrm{g})$ (Song and Yen, 2002), Ramaria botrytis (20.32 $\pm 0.7 \mathrm{mg} / \mathrm{g}$ ), Hypholoma fasciculare $\left(17.67 \pm 0.27 \mathrm{mg} . \mathrm{g}^{1}\right)$ (Barros et al., 2009) and significantly higher than those found in other species, such as Agaricus bisporus (4.49 $\pm 0.16 \mathrm{mg} / \mathrm{g})$, Lactarius deliciosus $(3.40 \pm 0.18 \mathrm{mg} / \mathrm{g})$ and Cantharellus cibarius (1.75 $\pm 0.50 \mathrm{mg} / \mathrm{g}$ ) (Barros et al., 2009).

Many G. lucidum-based products are available on the market in the form of tea, powders and extracts due to their beneficial human health properties (Xuanwei et al., 2007). They are normally produced from the fruiting body and cultured by solid state fermentation; however, this production method has serious disadvantages, including an extensive culture time (around six months), the difficulty in controlling product quality and the culture's susceptibility to environmental changes (Chang et al., 2006). Efforts have thus been directed towards producing bioactive substances in submerged fermentation, mainly by studying culture conditions and media formulated for producing biomass and metabolites such as polysaccharides and ganoderic acid (Yang and Liau, 1998; Yang et al., 2000; Fang et al., 2002; Tang and Zhong., 2002; Chang et al., 2006; Tang et al., 2010; Zhu et al., 2010). However, there are no reports of studies for producing phenolic compounds in submerged culture.

The present study thus established the composition of a culture medium for producing biomass and phenolic com- pounds from G. lucidum in submerged culture. A two-stage experimental strategy was used: 1) exploratory (a Plackett-Burman design was used for identifying the medium's key components) and 2) optimization (a central composite design was applied for optimizing their concentration). A desirability function was used in the latter stage for simultaneously optimizing both responses (i.e. biomass and phenolic compounds).

\section{Materials and Methods}

\section{Microorganism}

The G. lucidum basidiocarp (fruiting body) isolates were obtained from a commercial culture in Cumaral (Meta, Colombia) for the mycelium to be produced by the optimized culture medium. The fungi was conserved by plating it in YGC agar $\left(\mathrm{Oxoid}^{\mathbb{R}}\right)$ and incubated at $24{ }^{\circ} \mathrm{C}$ for nine days; discs of this agar were then placed in distilled sterile water and kept at $4{ }^{\circ} \mathrm{C}$.

\section{Culture media and growth conditions}

The culture medium used for inoculum reactivation and production was YGC agar $\left(\right.$ Oxoid $\left.^{\circledR}\right)$. The liquid fermentation medium consisted of a base solution (in $\mathrm{g} / \mathrm{L}: 1$, $\mathrm{K}_{2} \mathrm{HPO}_{4}$ Carlo Erba $^{\circledR} ; 1, \quad \mathrm{KH}_{2} \mathrm{PO}_{4}$ Merck $^{\circledR} ; 0.5$, $\mathrm{MnSO}_{4} .7 \mathrm{H}_{2} \mathrm{O}$ Merck $^{\circledR}$; 0.1, chloramphenicol Sigma ${ }^{\circledR}$ ), added from the substrates to be evaluated, according to the detailed experimental design described later on. The mycelium conserved at $4{ }^{\circ} \mathrm{C}$ was plated in YGC agar and incubated for nine days at $24{ }^{\circ} \mathrm{C}$. Seven discs of this agar $(6 \mathrm{~mm}$ diameter) were inoculated in $125 \mathrm{~mL}$ Erlenmeyer flasks with $35 \mathrm{~mL}$ liquid fermentation medium; they were incubated in a shaker at $120 \mathrm{rpm}$ for 10 days at $24^{\circ} \mathrm{C}$. All experiments were done in triplicate.

\section{Analytical methods}

Biomass production was measured as dry mass by membrane filtration and then dried in a convection oven for 96 hours at $60{ }^{\circ} \mathrm{C}$. The extracellular phenolic compounds (EPC) were quantified by treating the resulting fermentation medium with $50 \%(\mathrm{v} / \mathrm{v})$, final concentration, trichloroacetic acid (TCA) for precipitating proteins. This mix was then spun and the supernatant obtained; $\mathrm{pH}$ was adjusted to $3.5 \pm 0.5$ and two $1.5 \mathrm{~mL}$ aliquots were extracted. Polyvinyl-polypyrrolidone (PVPP) was added to one of these aliquots at $20 \%(\mathrm{p} / \mathrm{v})$ final concentration; this was vigorously mixed for 30 seconds and then spun at $4{ }^{\circ} \mathrm{C}$ for $10 \mathrm{~min}$ at $12000 \mathrm{rpm}$. The obtained supernatant was transferred to another tube and this procedure was repeated twice more. Total phenolic compounds concentration was determined in both TCA and PVPP treated extracts and extracts just treated with TCA, using the method reported by Cliffe et al. (1994). The reaction was kept for $30 \mathrm{~min}$ at room temperature before starting to read absorbance at $775 \mathrm{~nm}$ wavelength. Total phenolic compounds concentra- 
tion was calculated as being the difference between the concentration of extracts without PVPP and PVPP-treated extracts. The standard curve for this reaction was prepared using gallic acid. The evaluated extracts were kept at $-20{ }^{\circ} \mathrm{C}$ from the time of being collected until being analyzed.

\section{Experimental design}

\section{Selecting significant variables for a Plackett-Burman design (PBD)}

PBD was initially used for evaluating the relative importance of nine parameters in G. lucidum biomass production in submerged culture. The following were evaluated: three carbon sources (glucose, sucrose and lactose), two organic nitrogen sources (yeast extract and peptone), an inorganic nitrogen source (ammonium chloride), adding olive oil and thiamine to the culture medium and initial $\mathrm{pH}$ as culture condition. Table 1 gives the experimental design, along with the variables and levels which were evaluated; each variable's effects on biomass production were estimated as well as the difference between averages for high $(+)$ and low (-) measurements (23). Statgraphics Centurion 15.2 software was used for both design and statistical analysis, multiple regression and ANOVA.

\section{Optimizing a central composite design (CCD)}

A CCD was used for identifying optimum levels for the significant variables selected by PBD (Table 2) to obtain maximum biomass production $\left(Y_{l}\right)$ and maximum EPC concentration $\left(Y_{2}\right)$. The design consisted of eight factorial points, six axial points (star) and six central points in two blocks for a total of 20 experiments. The quadratic model for predicting the optimum point was expressed by the following equation:

$$
Y=b_{0}+\sum b_{i} X_{i}+\sum b_{i i} X_{i}^{2}+\sum b_{i j} X_{i} X_{j}
$$

where $Y$ was the response variable, $b$ the model's regression coefficient and $X$ the independent variables' coded levels.

Table 1 - Experimental variables at different levels in Plackett-Burman design for G. lucidum biomass production.

\begin{tabular}{lcccc}
\hline \multirow{2}{*}{ Code } & Variable & Units & \multicolumn{2}{c}{ Experimental levels } \\
\cline { 4 - 5 } & & & Lower (-) & Higher $(+)$ \\
\hline A & Glucose & $\mathrm{g} / \mathrm{L}$ & 10 & 20 \\
$\mathrm{~B}$ & Sucrose & $\mathrm{g} / \mathrm{L}$ & 8 & 16 \\
$\mathrm{C}$ & Lactose & $\mathrm{g} / \mathrm{L}$ & 10 & 20 \\
$\mathrm{D}$ & Yeast extract & $\mathrm{g} / \mathrm{L}$ & 2 & 5 \\
$\mathrm{E}$ & Peptone & $\mathrm{g} / \mathrm{L}$ & 2 & 5 \\
$\mathrm{~F}$ & Ammonium & $\mathrm{g} / \mathrm{L}$ & 2 & 5 \\
& chloride & & & \\
$\mathrm{G}$ & Olive oil & $\%(\mathrm{v} / \mathrm{v})$ & 0 & 3 \\
$\mathrm{H}$ & Initial $\mathrm{pH}$ & - & 5.5 & 6.5 \\
$\mathrm{I}$ & Thiamine & $\mathrm{mg} / \mathrm{L}$ & 0 & 50 \\
\hline
\end{tabular}

Table 2 - Independent variable levels tested for the central composite design.

\begin{tabular}{lccccccc}
\hline \multirow{2}{*}{ Code } & Variable & \multirow{2}{*}{ Units } & \multicolumn{5}{c}{ Experimental levels } \\
\cline { 3 - 8 } & & & -1.5 & -1 & 0 & +1 & +1.5 \\
\hline$X_{1}$ & Olive oil & $\%(\mathrm{v} / \mathrm{v})$ & 0 & 1 & 3 & 5 & 6 \\
$X_{2}$ & Yeast extract & $\mathrm{g} / \mathrm{L}$ & 3 & 6 & 12 & 18 & 21 \\
$X_{3}$ & Sucrose & $\mathrm{g} / \mathrm{L}$ & 25 & 30 & 40 & 50 & 55 \\
\hline
\end{tabular}

A desirability function (Eq. (2)) was used after the polynomial equations related to cell growth and EPC had been generated for selecting the most relevant factors for the response of interest in a combined response. This function was defined as being a shared function having two limiting values (minimum and maximum desirability), where values less than the established minimum were assumed to be 0 , whilst values exceeding the established maximum were assumed to be 1 .

$$
\begin{cases}0, & y \leq y_{\text {min }} \\ d=\frac{y-y_{\text {min }}}{y_{\text {max }}-y_{\text {min }}}, & y_{\text {min }} \leq y \leq y_{\text {max }} \\ 1, & y \geq y_{\text {max }}\end{cases}
$$

The values from the desirability functions for each replicate point, in each response evaluated (biomass and EPC) were obtained for generating a combined response; the geometric mean of both values were then calculated by assigning 3 and 5 coefficients of importance, respectively (Eq. (3)), thereby obtaining an average desirability index (D). The theoretical values used for adjusting the desirability function were assigned in line with the pertinent literature and experimental results; $18.7 \mathrm{~g} / \mathrm{L}$ was thus determined for biomass, since this value was the maximum for biomass reported in optimizing biomass production using $G$. lucidum (Chang et al., 2006) and the greatest experimental value obtained was used in the same design for EPC.

$$
D_{p}=\left(d_{b}^{3} \times d_{c}^{5}\right)^{1 / 8}
$$

Statgraphics Centurion 15.2 software was used for all design, statistical analysis, multiple regression and ANOVA operations.

\section{Chemical characterization of biomass and culture medium extracts}

Mature G. lucidum fruiting bodies obtained from the commercial culture and mycelium produced by the optimized culture medium were freeze-dried prior to solidliquid extraction fractionation with petroleum ether (benzene), dichloromethane $\left(\mathrm{CH}_{2} \mathrm{Cl}_{2}\right)$ and ethyl acetate (EtOAc). Each fraction was concentrated by vacuum evaporation after $96 \mathrm{~h}$ extraction. Concentrated fractions were then dissolved in the same solvent (for chemical characterization) or DMSO (for antifungal activity assay). The re- 
maining mycelium production culture medium was extracted by liquid-liquid fractionation in the same conditions as for fruiting bodies and mycelium.

The fractions were characterized by thin layer chromatography on silica gel plates (Alugram Nano-Sil $\mathrm{G} / \mathrm{UV}_{254}$ - Macherey-Nagel). The separated compounds were detected by vanillin staining (phenolics and steroids), antimony III chloride- $\mathrm{SbCl}_{3}$ (terpenoids), diphenylboric acid-2-aminoethyl ester-Neu reagent (flavonoids) and potassium hydroxide- $\mathrm{KOH}$ (coumarins), hydroxylamine-FeCl3 (lactones) and 2, 4-dinitrophenylhydrazine-2,4 DNPH (ketones) (Merck, 1980; Jork et al., 1990).

\section{Biomass and culture medium extract antifungal activity assay}

The biomass and culture medium extracts' antifungal activity regarding two clinical Aspergillus sp. isolates (strains 1 and 10) was evaluated by disk diffusion test following National Committee for Clinical Laboratory Standards guidelines (2003). Whatman grade No. 1 filter paper disks (6 mm diameter) were activated with $100 \mu \mathrm{g}$ of each extract or $25 \mu \mathrm{g}$ terbinafine as positive control for inhibiting fungal growth.

\section{Results and Discussion}

\section{Plackett-Burman design}

PBD methodology is a powerful and useful tool which is used for the rapid screening of key variables in a multivariable system; even though it does not determine exact amounts, it does provide important information about each factor by using very few experiments (Plackett and Burman, 1946; De Souza et al., 2008; Prasad et al., 2010). A 12 experiment PBD was used during the first optimization phase for evaluating the effect of nine variables (glucose, sucrose, lactose, yeast extract, peptone, ammonium chloride, olive oil, thiamine and initial $\mathrm{pH}$ ) on biomass production from G. lucidum. The variables' interaction on two levels in PBD has revealed that yeast extract $(\mathrm{p}=0.027)$ and olive oil $(\mathrm{p}=0.006)$ significantly affect $G$. lucidum growth (Table 3).

Similar results have been obtained by other authors; a positive relationship has been found between adding olive oil and biomass production using G. lucidum and when using Cordyceps militaris (Park et al., 2002). The olive oil is formed by several fatty acids, such as oleic, linoleic and linolenic acid, their main component being oleic acid (55\%-83\%). Song and Yen (2002), have proposed that oleic acid is able to directly incorporate itself into fungi cell membrane, increasing its fluidity and thereby facilitating the entry of other substrates present in culture medium. On the other hand, yeast extract is a vitamin B complex source (growth factors), amino acids, peptides and some carbohydrates, supporting effective cell development. Similar results have been obtained by Chang et al. (2006), whom found that yeast extract and olive oil are two substrates significantly influencing biomass development when using $G$. lucidum. Fang et al. (2002), have also reported that adding

Table 3 - Plackett Burman design results. The medium components and initial $\mathrm{pH}$ significance on G. lucidum biomass production are showed after 10 fermentation days.

\begin{tabular}{|c|c|c|c|c|c|c|c|c|c|c|}
\hline \multirow[t]{2}{*}{$\operatorname{Exp} \mathrm{N}^{o}$} & \multicolumn{9}{|c|}{ Variable code } & \multirow{2}{*}{$\begin{array}{c}\text { Biomass* } \\
(\mathrm{g} / \mathrm{L})\end{array}$} \\
\hline & $\mathrm{A}$ & $\mathrm{B}$ & $\mathrm{C}$ & $\mathrm{D}$ & $\mathrm{E}$ & $\mathrm{F}$ & G & $\mathrm{H}$ & I & \\
\hline 1 & + & + & - & + & + & - & + & - & - & $12.6 \pm 0.4$ \\
\hline 2 & + & - & - & - & + & + & + & - & + & $7.3 \pm 0.6$ \\
\hline 3 & + & + & - & + & - & - & - & + & + & $4.3 \pm 0.7$ \\
\hline 4 & + & + & + & - & + & + & - & + & - & $2.6 \pm 0.2$ \\
\hline 5 & - & - & - & + & + & + & - & + & + & $4.8 \pm 0.1$ \\
\hline 6 & - & - & - & - & - & - & - & - & - & $2.3 \pm 0.3$ \\
\hline 7 & - & + & + & + & - & + & + & - & + & $9.6 \pm 1.4$ \\
\hline 8 & - & + & - & - & - & + & + & + & - & $7.8 \pm 0.6$ \\
\hline 9 & + & - & + & - & - & - & + & + & + & $9.7 \pm 1.6$ \\
\hline 10 & + & - & + & + & - & + & - & - & - & $5.6 \pm 0.1$ \\
\hline 11 & - & - & + & + & + & - & + & + & - & $12.1 \pm 1.1$ \\
\hline 12 & - & + & + & - & + & - & - & - & + & $3.7 \pm 0.4$ \\
\hline Effect & 0.170 & 0.090 & 0.160 & 1.330 & 0.270 & -0.770 & 2.960 & 0.220 & -0.110 & \\
\hline F-value & 0.604 & 0.160 & 0.542 & 36.209 & 1.475 & 12.150 & 178.739 & 0.968 & 0.244 & \\
\hline P-value & 0.519 & 0.728 & 0.538 & $0.027^{\mathrm{a}}$ & 0.349 & 0.073 & $0.006^{\mathrm{a}}$ & 0.429 & 0.670 & \\
\hline
\end{tabular}

*Results shown are average of three replicate experiments.

${ }^{a}$ Significant at $95 \%$ confidence. 
organic nitrogen sources significantly promotes greater fungal growth during liquid fermentation, suggesting that some amino acids cannot be synthetized from inorganic nitrogen sources.

Regarding carbon source, no significant effect was detected for any of the three sources evaluated: glucose $(p=0.5179)$, sucrose $(p=0.728)$ or lactose $(p=0.538)$. Contradictory reports about this are found in the literature, since it has been shown that sucrose (in brown sugar form) has a stimulating effect on biomass production when using $G$. lucidum (Chang et al., 2006), whilst other authors, such as Tang and Zhong (2002), have found that lactose was the best carbon source for biomass and ganoderic acid production by the G. lucidum CCGMC 5.616 strain and that sucrose was the carbohydrate which least promoted biomass production. Bearing the foregoing in mind, the decision to use sucrose as carbon source for later optimization was based on the results obtained in this work, since PBD did not detect differences or negative effects for the sugars evaluated regarding biomass production and/or the economic aspect.

\section{Central composite design}

A full $2^{3}$ factorial design (eight factorial points) was used in the second optimization phase, increased by six ax- ial points (star) and six central point replicates, giving a total of 20 experiments, for optimizing the concentration of olive oil $\left(X_{1}\right)$, yeast extract $\left(X_{2}\right)$ and sucrose $\left(X_{3}\right)$ in the culture medium. Table 4 shows the results of these experiments, as well as the values predicted by the second order model for the three response variables $\left(Y_{1}\right.$, biomass; $Y_{2}$, $\mathrm{CEF}$ and $\left.Y_{3}, D\right)$.

Table 5 presents the corresponding analysis of variance (ANOVA) results. The coefficient of determination $\left(\mathrm{R}^{2}\right)$ value provided a measure of how the variability in values observed in the response variables could be explained by the experimental factors and their interactions. So, the model's $\mathrm{R}^{2}$ (Table 5) (0.879 for $Y_{1}, 0.807$ for $Y_{2}$ and 0.855 for $Y_{3}$ ) indicated that the model could explain $87.9 \%$, $80.7 \%$ and $85.5 \%$, respectively, of total variation in each case. $\mathrm{P}$ values $\left(0.0047\right.$ for $Y_{1}, 0.0457$ for $Y_{2}$ and 0.0163 for $Y_{3}$ ) showed that the model represented a good prediction for the experimental results. When each response was separately analyzed, it was observed that olive oil had a significant influence on both lineal $(\mathrm{p}=0.0013)$ and quadratics terms $(\mathrm{p}=0.0004)$ regarding $G$. lucidum growth $\left(Y_{l}\right)$. EPC concentration $\left(Y_{2}\right)$ was seen to be influenced by yeast extract $(\mathrm{p}=0.0275$, lineal term, $\mathrm{p}=0.0148$ quadratic term). Regarding the combined response of biomass and EPC (D),

Table 4 - Central composite design results. The coded values of independent variables and obtained and predicted values for the three response variables are showed. The biomass and EPC responses were determined after 10 fermentation days.

\begin{tabular}{|c|c|c|c|c|c|c|c|c|c|}
\hline \multirow[t]{3}{*}{ Run } & \multicolumn{3}{|c|}{ Independent variables (in coded value) } & \multicolumn{6}{|c|}{ Response variables } \\
\hline & \multirow[t]{2}{*}{$X_{1}$} & \multirow[t]{2}{*}{$X_{2}$} & \multirow[t]{2}{*}{$X_{3}$} & \multicolumn{2}{|c|}{ Biomass $(\mathrm{g} / \mathrm{L})$} & \multicolumn{2}{|c|}{$\mathrm{EPC}(\mathrm{g} / \mathrm{L})$} & \multicolumn{2}{|c|}{$\mathrm{D}$} \\
\hline & & & & $\begin{array}{l}\text { Obtained } \\
\text { value }\end{array}$ & $\begin{array}{l}\text { Predicted } \\
\text { value }\end{array}$ & $\begin{array}{l}\text { Obtained } \\
\text { value }\end{array}$ & $\begin{array}{l}\text { Predicted } \\
\text { value }\end{array}$ & $\begin{array}{l}\text { Obtained } \\
\text { value }\end{array}$ & $\begin{array}{l}\text { Predicted } \\
\text { value }\end{array}$ \\
\hline 1 & +1 & -1 & +1 & $9.0 \pm 2.1$ & 9.28 & $0.0122 \pm 0.002$ & 0.0200 & 0.289 & 0.374 \\
\hline 2 & +1 & +1 & -1 & $13.1 \pm 0.5$ & 11.86 & $0.0388 \pm 0.003$ & 0.0377 & 0.683 & 0.642 \\
\hline 3 & -1 & +1 & +1 & $5.2 \pm 0.8$ & 5.00 & $0.0576 \pm 0.026$ & 0.0490 & 0.618 & 0.530 \\
\hline 4 & +1 & -1 & -1 & $7.0 \pm 1.7$ & 7.09 & $0.0066 \pm 0.006$ & 0.0141 & 0.178 & 0.235 \\
\hline 5 & -1 & +1 & -1 & $6.9 \pm 0.4$ & 6.58 & $0.0382 \pm 0.084$ & 0.0293 & 0.532 & 0.416 \\
\hline 6 & 0 & 0 & 0 & $10.1 \pm 1.8$ & 10.98 & $0.0410 \pm 0.021$ & 0.0379 & 0.641 & 0.635 \\
\hline 7 & +1 & +1 & +1 & $11.2 \pm 0.7$ & 10.79 & $0.0413 \pm 0.018$ & 0.0370 & 0.669 & 0.600 \\
\hline 8 & -1 & -1 & +1 & $5.7 \pm 1.1$ & 6.89 & $0.0362 \pm 0.007$ & 0.0361 & 0.479 & 0.489 \\
\hline 9 & -1 & -1 & -1 & $4.9 \pm 0.1$ & 5.20 & $0.0067 \pm 0.002$ & 0.0098 & 0.158 & 0.195 \\
\hline 10 & 0 & 0 & 0 & $11.2 \pm 2.4$ & 10.98 & $0.0333 \pm 0.012$ & 0.0379 & 0.585 & 0.635 \\
\hline 11 & 0 & 0 & 0 & 11.51 .0 & 10.98 & $0.0299 \pm 0.011$ & 0.0379 & 0.553 & 0.635 \\
\hline 12 & 0 & -1.5 & 0 & $8.3 \pm 1.2$ & 7.05 & $0.0001 \pm 0.000$ & -0.0113 & 0.014 & -0.126 \\
\hline 13 & +1.5 & 0 & 0 & $5.2 \pm 0.5$ & 5.97 & $0.0107 \pm 0.005$ & 0.0048 & 0.216 & 0.180 \\
\hline 14 & -1.5 & 0 & 0 & $0.9 \pm 0.6$ & 0.21 & $0.0001 \pm 0.000$ & 0.0105 & 0.006 & 0.097 \\
\hline 15 & 0 & 0 & 0 & $10.9 \pm 2.2$ & 8.75 & $0.0323 \pm 0.005$ & 0.0221 & 0.569 & 0.394 \\
\hline 16 & 0 & 0 & 0 & $6.6 \pm 2.5$ & 8.75 & $0.0239 \pm 0.004$ & 0.0221 & 0.390 & 0.394 \\
\hline 17 & 0 & 0 & +1.5 & $8.8 \pm 1.2$ & 8.18 & $0.0419 \pm 0.003$ & 0.0461 & 0.618 & 0.645 \\
\hline 18 & 0 & +1.5 & 0 & $7.9 \pm 1.0$ & 9.22 & $0.0001 \pm 0.000$ & 0.0160 & 0.014 & 0.209 \\
\hline 19 & 0 & 0 & 0 & $9.1 \pm 2.2$ & 8.75 & $0.0197 \pm 0.009$ & 0.0221 & 0.390 & 0.394 \\
\hline 20 & 0 & 0 & -1.5 & $7.0 \pm 0.4$ & 7.72 & $0.0266 \pm 0.005$ & 0.0269 & 0.427 & 0.456 \\
\hline
\end{tabular}


Table 5 - Central composite design variance analysis. The desirability was determined using importance coefficients of 3 and 5 for biomass and EPC, respectively.

\begin{tabular}{|c|c|c|c|c|c|c|}
\hline \multirow[t]{2}{*}{ Factor } & \multicolumn{2}{|c|}{ Biomass $\left(Y_{l}\right)$} & \multicolumn{2}{|c|}{$\operatorname{EPC}\left(Y_{2}\right)$} & \multicolumn{2}{|c|}{$\mathrm{D}\left(Y_{3}\right)$} \\
\hline & P-value & Estimated effect & P-value & Estimated effect & P-value & Estimated effect \\
\hline$X_{I}$ & $0.0013^{\mathrm{a}}$ & 1.92 & 0.6517 & 0.007 & 0.4652 & 0.112 \\
\hline$X_{2}$ & 0.1156 & 0.72 & $0.0275^{\mathrm{a}}$ & 0.037 & $0.0133^{\mathrm{a}}$ & 0.063 \\
\hline$X_{3}$ & 0.7215 & 0.15 & 0.0780 & 0.028 & 0.1161 & -0.113 \\
\hline$\left(X_{I}\right)^{2}$ & $0.0004^{\mathrm{a}}$ & -2.52 & 0.1397 & -0.026 & $0.0209^{\mathrm{a}}$ & -0.156 \\
\hline$\left(X_{2}\right)^{2}$ & 0.5694 & -0.27 & $0.0148^{\mathrm{a}}$ & -0.048 & $0.0038^{\mathrm{a}}$ & 0.070 \\
\hline$\left(X_{3}\right)^{2}$ & 0.4631 & -0.36 & 0.0582 & 0.034 & 0.1194 & 0.047 \\
\hline$X_{1}^{*} X_{2}$ & 0.1360 & 0.85 & 0.5641 & 0.011 & 0.3316 & -0.039 \\
\hline$X_{1} * X_{3}$ & 0.8133 & 0.13 & 0.7676 & -0.005 & 0.4144 & -0.045 \\
\hline$X_{2} * X_{3}$ & 0.1512 & -0.81 & 0.8415 & 0.004 & 0.3474 & 0.112 \\
\hline Intercept & - & 9.87 & - & 0.18 & - & 0.51 \\
\hline Model & $0.0047^{\mathrm{a}}$ & - & $0.0457^{\mathrm{a}}$ & - & $0.0163^{\mathrm{a}}$ & - \\
\hline Lack of fit & 0.6644 & - & 0.0734 & - & 0.1052 & - \\
\hline $\mathrm{R}^{2}$ & 0.879 & - & 0.807 & - & 0.855 & - \\
\hline $\mathrm{R}^{2}$ (fitted) & 0.770 & - & 0.633 & - & 0.644 & - \\
\hline
\end{tabular}

${ }^{\text {a }}$ Significant at $95 \%$ confidence.

the influence of yeast extract $(\mathrm{p}=0.0133$ lineal term, $\mathrm{p}=0.0038$ quadratic term) and olive oil ( $\mathrm{p}=0.0209$ quadratic term) was observed. Sucrose did not have a significant influence regarding any of the three responses.

It was not surprising that the two variables significantly affecting biomass production $\left(X_{1}\right.$ and $\left.X_{2}\right)$ in PBD (Table 3 ) had equal positive influence when analyzing the combined response in CCD (Table 5). It is well-known that the synthesis of phenolic compounds in most plants, fungi and bacteria happens through the shikimic acid route where they become simple glycolysis-derived carbohydrate precursors, and the pentose shikimic acid pathway which is the precursor for most aromatic compounds in the cell (Mandal et al., 2010). Such synthesis could thus be promoted by a continuous carbon flow towards the cell (Ryan et al., 2002). Results obtained by some other authors have suggested that increased biomass in G. lucidum is directly related to the production of metabolites such as ganoderic acid and polysaccharides (Fang and Zhong, 2002; Tang and Zhong, 2002; Tang et al., 2010), such results being similar to those found in this study for EPCs.

The relationship between both significant variables $\left(X_{1}\right.$ y $\left.X_{2}\right)$ and the responses variables can be visualized in the Figure 1. The surface response curvature reflected the two independent variables' degree of influence on the dependent variables: Biomass (Figure 1A), EPC (Figure 1B) and $\mathrm{D}$ (Figure $1 \mathrm{C}$ ), whilst the third variable $\left(X_{3}\right)$ maintained its central value. Canonic analysis of the regression equation (Eq. (4)) revealed that the optimum concentration for the three variables leading to obtaining the maximum D response was 2.99, 13.29 and $50.00(\mathrm{~g} / \mathrm{L})$ for olive oil $\left(X_{1}\right)$, yeast extract $\left(X_{2}\right)$ and sucrose $\left(X_{3}\right)$, respectively.

$$
\begin{aligned}
& D=-0.226+0.2147 X_{1}+0.1412 X_{2}-0.0346 X_{3}- \\
& 0.0283 X_{1}^{2}-4.3429^{-3} X_{2}^{2}+6.9654^{-4} X_{3}^{2}+ \\
& 3.8750^{-3} X_{1} X_{2}-1.9375^{-3} X_{1} X_{2}-7.500^{-4} X_{1} X_{3}
\end{aligned}
$$

A validation experiment was carried out using the model's predicted values, maximum biomass production was $9.35 \mathrm{~g} / \mathrm{L}$ (the average of three repeats: $0.535 \mathrm{SD}$ ) and that for phenolic compounds was $0.0452 \mathrm{~g} / \mathrm{L}$ (the average for three repeats: $0.0064 \mathrm{SD}$ ). Comparatively, the expected desirability index was 0.653 and the experimentally index obtained (using same maximum and minimum values established for DCC) was 0.662, demonstrating the effectiveness of the method. This value was $100 \%$ higher than that obtained in the growth medium usually used in the laboratory (data not shown), indicating that optimization had been satisfactory.

\section{Biomass and culture medium extract chemical characterization and antifungal activity}

Chemical characterization revealed similar metabolite patterns for mature fruiting bodies and mycelium extracts, except for coumarins and lactones (Table 6), while terpenoids were only detected in the benzene fraction in culture medium extracts. It is probable that metabolite concentration in culture medium extracts was too low to be detected by TLC staining, but was sufficient to inhibit Aspergillus sp. growth (Table 6). The benzene extracts did not prevent Aspergillus sp. isolates growth, thereby confirming $G$. lucidum bioactive compounds' polar nature (Ofodile et al., 2005). Another G. lucidum polar compound (ganodermin) has demonstrated mycelia growth inhibition 

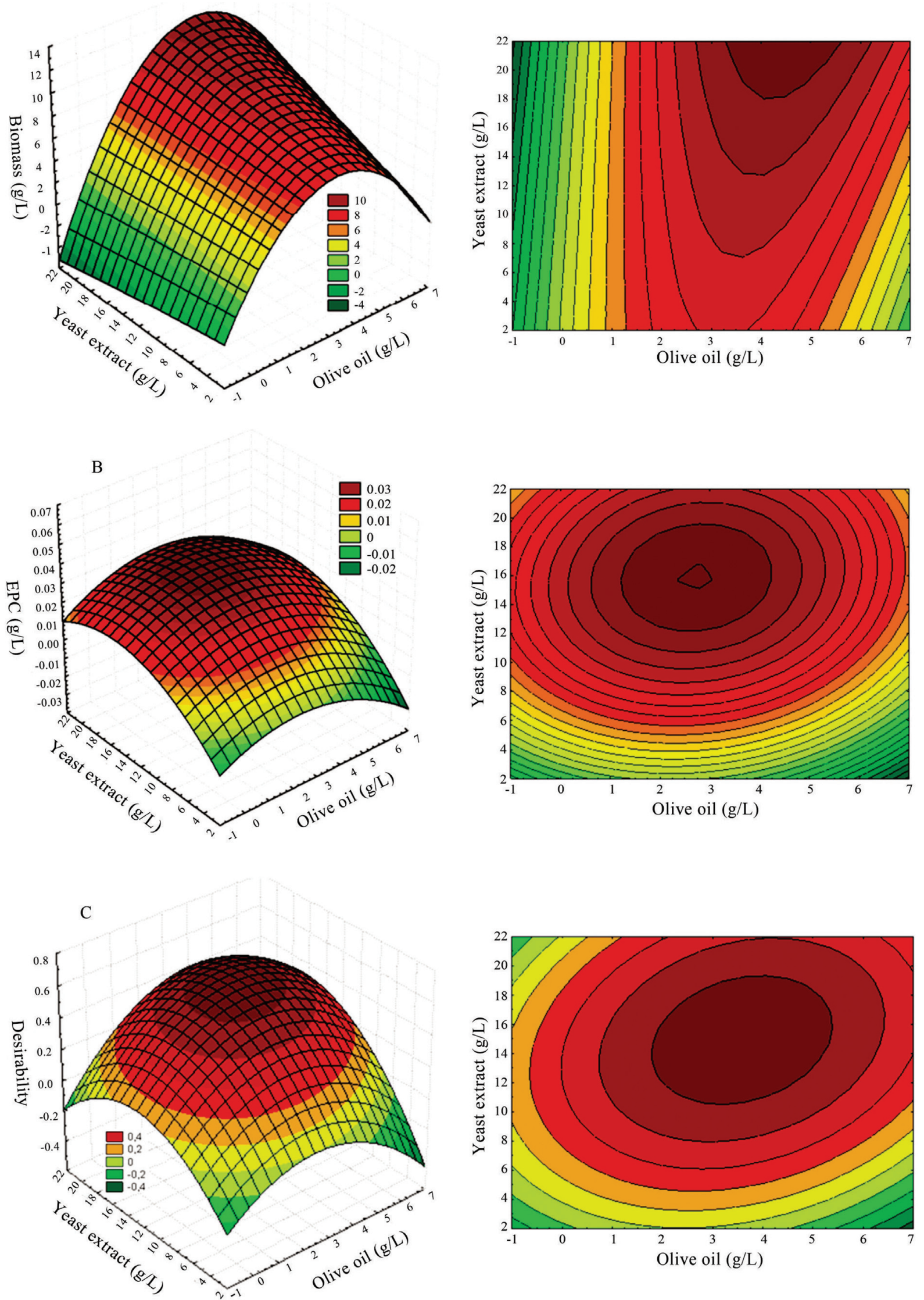

Figure 1 - 3D response surface and contours plot, showing interactive effects of olive oil $\left(X_{1}\right)$ and yeast extract $\left(X_{2}\right)$, sacarose $\left(X_{3}\right)$ maintained at $30 \mathrm{~g} / \mathrm{L}$. Effects over: A. Biomass (g/L), B. EPC (g/L) and C. Desirability. 


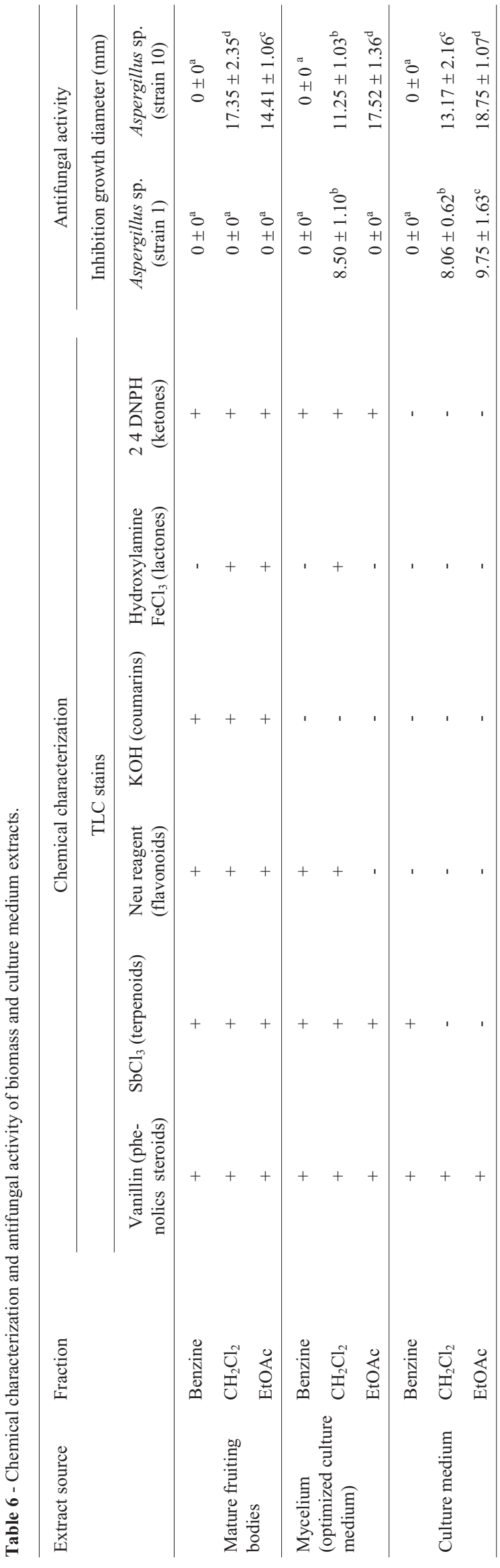

of phytopathogens such as Botrytis cinerea, Fusarium oxysporum and Physalospora piricola (Vaz et al., 2011).

Medium optimization research for G. lucidum has been focused on polysaccharide and terpenoid synthesis (Chang et al., 2006, Fang and Zhong, 2002; Tang et al., 2010), leaving apart other metabolites having diverse biological activity, such as flavonoids and ketones. Such metabolites (detected in mature fruiting bodies and mycelium extracts) have been shown to have antifungal activity regarding clinical fungal isolates (Cushnie and Lamb, 2005; Kocsis et al., 2009).

\section{Conclusion}

It has been shown in this study how a culture medium for production biomass and phenolic compounds by using Ganoderma lucidum was optimized by using a statistical design strategy combining Plackett-Burman design, central composite design and a desirability function for optimizing both factors simultaneously. Biomass production was obtained in the optimized medium which was $100 \%$ greater than that obtained in the media usually employed in the laboratory and extracts having a biological composition and activity similar to that obtained in fruiting bodies. This showed, once more, that these methods are very useful for optimizing fermentation and, in the specific case of $G$. lucidum, optimizing processes for producing it and its metabolites in submerged culture as a sound alternative to traditional culture.

\section{Acknowledgments}

We would like to thank Pontificia Universidad Javeriana for financing this project (ID project 002952).

\section{Abbreviatures}

TCA: Trichloroacetic acid.

PVPP: Polyvinyl-polypyrrolidone.

PBD: Plackett-Burman design.

CCD: Central composite design.

D: Extra average desirability index.

EPC: Extracellular phenolic compounds.

\section{References}

Barros L, Dueñas M, Ferreira IC, Baptista P, Santos-Buelga C (2009) Phenolic acids determination by HPLC-DADESI/MS in sixteen different Portuguese wild mushrooms species. Food Chem Toxicol 47:1076-1079.

Chang MY, Tsai GJ, Houng JY (2006) Optimization of the medium composition for the submerged culture of Ganoderma lucidum by Taguchi array design and steepest ascent method. Enzyme Microbial Technol 38:407-414.

Cliffe S, Fawer M, Maier G, Takata K, Ritter G (1994) Enzyme assays for the phenolic content of natural juices. J Agricult Food Chem 42:1824-1828.

Cushnie T, Lamb AJ (2005) Antimicrobial activity of flavonoids. Int J Antimicrob Ag 26:343-356. 
De Souza RA, Batista FS, Gomes FLS (2008) Production of 6-pentyl- $\alpha$-pyrone by Trichoderma harzianum in solid-state fermentation. Braz J Microbiol 39:712-717.

Del Signore A, Romeo F, Giaccio M (1997) Content of phenolic substances in basidiomycetes. Mycol Res 101:552-556.

Fang QH, Tang YJ, Zhong JJ (2002) Significance of inoculation density control in production of polysaccharide and ganoderic acid by submerged culture of Ganoderma lucidum. Process Biochem 37:1375-1379.

Fang QH, Zhong JJ (2002) Submerged fermentation of higher fungus Ganoderma lucidum for production of valuable bioactive metabolites-ganoderic acid and polysaccharide. Biochem Eng J 10:61-65.

Jork H, Funk W, Fischer W, Wimmer H (1990) Thin-layer chromatography. Reagents and detection methods. VCH, Weinheim, Federal Republic of Germany.

Kocsis B, Kustos I, Kilár F, Nyul A, Jakus PB, Kerekes S, Villarreal V, Prókai L, Loránd T (2009) Antifungal unsaturated cyclic Mannich ketones and amino alcohols: Study of mechanism of action. Eur J Med Chem 44:1823-1829.

Lai CY, Hung JT, Lin HH, Yu AL, Chen SH, Tsai YC, Shao LE, Yang WB, Yu J (2010) Immunomodulatory and adjuvant activities of a polysaccharide extract of Ganoderma lucidum in vivo and in vitro. Vaccine 28:4945-4954.

Leskosek-Cukalovic I, Despotovic S, Lakic N, Niksic M, Nedovic V, Tesevic V (2010) Ganoderma lucidum - Medical mushroom as a raw material for beer with enhanced functional properties. Food Res Int 43:2262-2269.

Mandal SM, Chakraborty D, Dey S (2010) Phenolic acids act as signaling molecules in plant-microbe symbioses. Plant Signaling \& Behavior 5:359-368.

Mau JL, Tsai S-Y, Tseng Y-H, Huang S-J (2005) Antioxidant properties of hot water extracts from Ganoderma tsugae Murrill. LWT 38:589-597.

Mei-Chun K, Ching-Yi W, Choi-Lan H, Ming-Jiuan W (2006) Ganoderma lucidum mycelia enhance innate immunity by activating NF-kB. J Ethnopharmacol 103:217-222.

Merck (1980) Dyeing reagents for thin layer and paper chromatography. Merck, Darmstadt, Germany.

Muller CI, Kumagai T, O'Kelly J, Seeram NP, Heber D, Koeffler HP (2006) Ganoderma lucidum causes apoptosis in leukemia, lymphoma and multiple myeloma cells. Leuk Res 30:841-848.

National Committee for Clinical Laboratory Standards (2003) Method for Antifungal Disk Diffusion Susceptibility Testing of Yeasts: Proposed Guideline M44-P. National Committee for Clinical Laboratory Standard, Wasyne.

Ofodile L, Uma N, Kokubun T, Grayer R, Ogundipe O, Simmonds M (2005) Antimicrobial activity of some Ganoderma species from Nigeria. Phytotherapy Res 19:310-313.

Park J, Kim S, Hwang H, Cho J, Yun J (2002) Stimulatory effect of plant oils and fatty acids on the exo-biopolymer production in Cordyceps militaris. Enzyme Microbial Technol 31:250-255.

Plackett R, Burman J (1946) The design of optimum multifactorial experiments. Biometrika 33:305-325.
Prasad PB, Javed S, Ali M (2010) Production of Angkak through co-culture of Monascus purpureus and Monascus ruber. Braz J Microbiol 41:757-764.

Ribeiro B, Lopes R, Andrade PB, Seabra RM, Goncalves RF, Baptista P, Quelhas I, Valentao P (2008) Comparative study of phytochemicals and antioxidant potential of wild edible mushroom caps and stipes. Food Chem 110:47-56.

Russell M, Paterson R (2006) Ganoderma - A therapeutic fungal biofactory. Phytochemistry 67:1985-2001.

Ryan D, Antolovich M, Prenzler P, Robards K, Lavee S (2002) Biotransformaions of phenolic compounds in Olea europea. Eur Sci Hortic 92:147-176.

Saltarelli R, Ceccaroli P, Lotti M, Zambonelli A, Buffalini M, Casadei L, Vallorani L, Stocchi V (2009) Biochemical characterisation and antioxidant activity of mycelium of Ganoderma lucidum from Central Italy. Food Chem 116:143-151.

Song T, Yen G (2002) Antioxidant properties of Antrodia camphorata in submerged culture. J Agricult Food Chem 50:3322-3327.

Sudheesh N, Ajith T, Ramnath V, Janardhanan K (2010) Therapeutic potential of Ganoderma lucidum (Fr.) P. Karst. against the declined antioxidant status in the mitochondria of post-mitotic tissues of aged mice. Clin Nutr 29:406-412.

Tang YJ, Zhang W, Liu RS, Zhu LW, Zhong J-J (2010) Scale-up study on the fed-batch fermentation of Ganoderma lucidum for the hyperproduction of ganoderic acid and Ganoderma polysaccharides. Process Biochem doi:10.1016/j.procbio.2010.08.013.

Tang YJ, Zhong JJ (2002) Fed-batch fermentation of Ganoderma lucidum for hyperproduction of polysaccharide and ganoderic acid. Enzyme Microbial Technol 31:20-28.

Vaz JA, Barros L, Martins A, Morais JS, Vasconcelos HM, Ferreira IC (2011) Phenolic profile of seventeen Portuguese wild mushrooms. Food Sci Technol 44:343-346.

Wang H (2006) Ganodermin, an antifungal protein from fruiting bodies of the medicinal mushroom Ganoderma lucidum. Peptides 44:27-30.

Xuanwei Z, Juan L, Yizhou Y, Jingya Y, Xiaofen S, Kexuan T (2007) Ganodermataceae natural products and their related pharmacological functions. Am J Chin Med 35:559-574.

Yang FC, Ke YF, Kuo SS (2000) Effect of fatty acids on the mycelial growth and polysaccharide formation by Ganoderma lucidum in shake flask cultures. Enzyme Microbial Technol 27:295-301.

Yang F-C, Liau C-B (1998) The influence of environmental conditions on polysaccharide formation by Ganoderma lucidum in submerged cultures. Process Biochem 33:547-553.

Zhu LW, Zhong JJ, Tang YJ (2010) Multi-fed batch culture integrated with three-stage light irradiation and multiple additions of copper ions for the hyperproduction of ganoderic acid and Ganoderma polysaccharides by the medicinal mushroom Ganoderma lucidum. Process Biochem doi:10.1016/j.procbio.2010.03.010.

All the content of the journal, except where otherwise noted, is licensed under a Creative Commons License CC BY-NC. 